\title{
Fludrocortisone in the treatment of hypotensive disorders in the elderly
}

\author{
Raja M Hussain, Shona J McIntosh, Joanna Lawson, Rose Anne Kenny
}

\author{
Abstract \\ Objective-To evaluate tolerance of flu- \\ drocortisone in older patients with \\ hypotensive disorders. \\ Design-Prospective case series. \\ Setting-Syncope clinic.
}

Patients-64 Consecutive patients over 65 years (mean age 80 years) with one or more hypotensive disorders (orthostatic hypotension, vasodepressor carotid sinus syncope, and/or vasodepressor neurocardiogenic syncope.

Interventions-Fludrocortisone in daily doses of $100 \mathrm{mg}(72 \%), 50 \mathrm{mg}(27 \%)$, and $200 \mathrm{mg}$ (one patient).

Main outcome measures-Adverse events, treatment withdrawal.

Results-During follow up 13 patients died of unrelated causes. Of the remainder $33 \%$ discontinued fludrocortisone at a mean of five months. Reasons for discontinuing treatment were hypertension, five; cardiac failure, four; depression, three; oedema, three; and unspecified, two. In those who continued treatment supine systolic and diastolic blood pressure did not differ significantly from baseline (follow up two to 21 months). Hypokalaemia developed in $24 \%$ at a mean of eight months; in no case was treatment withdrawn because of hypokalaemia.

Conclusion-Fludrocortisone, even in low doses, is poorly tolerated in the long term in older patients with hypotensive disorders.

(Heart 1996;76:507-509)

Keywords: fludrocortisone; hypotensive disorders; adverse effects; elderly patients

Cardiovascular Investigation Unit, Royal Victoria Infirmary, Newcastle upon Tyne

$R M$ Hussain

S J McIntosh

J Lawson

R A Kenny

Correspondence to:

Professor R A Kenny,

Cardiovascular Investigation

Cardiovascular Invesie

Unit, Royal Victoria

Infirmary, and School of

Medicine, University of

Newcastle Upon Tyne,

NE1 4LP.

Accepted for publication

29 May 1996
Fludrocortisone is a synthetic mineralocorticoid which increases pressor sensitivity to circulating catecholamines and angiotensin, alters intravascular volume, and has central adrenergic effects. ${ }^{1}$ It is beneficial in the treatment of hypotensive disorders: orthostatic hypotension, vasodepressor carotid sinus syndrome, and vasodepressor neurocardiogenic syndrome. In younger patients the most frequently reported adverse events are supine hypertension, cardiac failure, and hypokalaemia. ${ }^{2}$ Fludrocortisone is commonly prescribed for older patients, yet in our clinical experience it is poorly tolerated during prolonged treatment. The objective of this study was to evaluate tolerance to fludrocortisone in consecutive elderly patients treated for common hypotensive disorders.

Patients and methods

The study population comprised a series of patients over 65 years recruited from the syncope clinic in the Royal Victoria Infirmary during one year. All presented with syncope, dizziness and/or unexplained falls. Baseline investigations included a full clinical assessment, heamatology screen, biochemical profile, 12 lead electrocardiogram, 24 hour ambulatory blood pressure monitoring (Space labs, Wokingham, model number 90207), 24 hour ambulatory cardiac monitoring (Delmar, Numed, Sheffield), foot-plate-assisted head up tilt to $70^{\circ}$ for 30 minutes, carotid sinus massage (supine and upright), and autonomic function tests. ${ }^{3}$ All manoeuvres were monitored using continuous blood pressure (Finapres digital photoplethysmography) and heart rate (surface ECG) recording. Supine blood pressures were additionally assessed by sphygmomanometer readings. Patients who had clinical evidence of cardiac failure ${ }^{4}$ peripheral oedema, or supine systolic blood pressure greater than $180 \mathrm{~mm} \mathrm{Hg}$, or biochemical evidence of renal dysfunction (urea and/or creatinine above normal range) were not recruited for fludrocortisone treatment. Participants were reviewed every two weeks, until symptom benefit was achieved and thereafter every two months. At review, patients had supine blood pressure and serum potassium measurement in addition to semi-structured questions about adverse drug events.

DIAGNOSTIC CRITERIA FOR VASODEPRESSOR DISORDERS

\section{Orthostatic hypotension}

Orthostatic hypotension was defined as either a fall in systolic blood pressure exceeding $20 \mathrm{~mm} \mathrm{Hg}$ after two minutes of standing (unsupported) or a fall in systolic blood pressure to less than $90 \mathrm{~mm} \mathrm{Hg}$, both in association with symptom reproduction. ${ }^{5}$

\section{Vasodepressor carotid sinus syndrome}

Vasodepressor carotid sinus syndrome was defined as a greater than $50 \mathrm{~mm} \mathrm{Hg}$ fall in systolic blood pressure during carotid sinus massage, either supine or upright, independent of heart rate slowing. ${ }^{6}$

Vasodepressor neurocardiogenic syncope

Type 1, mixed-Heart rate initially increases 
Number of patients who had orthostatic hypotension $(\mathrm{OH})$, vasodepressor neurocardiogenic syncope (VDNCS), and vasodepressor carotid sinus syndrome (VDCSS) before treatment with fludrocortisone.

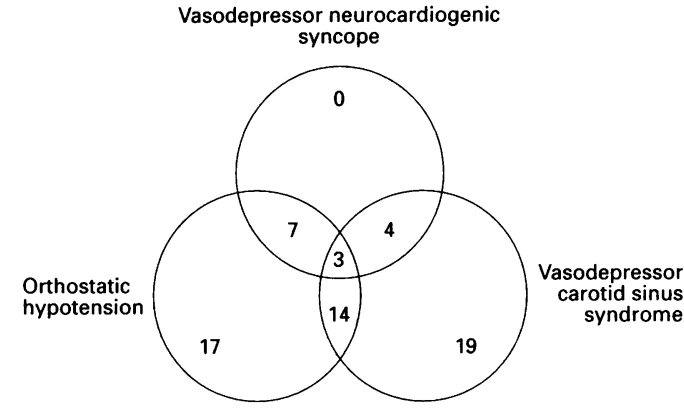

during head up tilt and later decreases, but remains above 40 beats/min or is less than 40 beats/min only briefly ( $<10$ seconds).

Type 2, pure vasodepressor-Heart rate increases initially and then decreases to less than $10 \%$ of peak value at the time of syncope. A reduction in blood pressure accounts for syncope or presyncope.?

\section{Definition of adverse effects}

Hypokalaemia is defined as a serum potassium of less than $3.5 \mathrm{mmol} / \mathrm{l}$; hypertension as a supine systolic blood pressure of greater than $200 \mathrm{~mm} \mathrm{Hg}$ and/or diastolic blood pressure of greater than $100 \mathrm{~mm} \mathrm{Hg}$; cardiac failure was classified by New York Heart Association criteria. $^{4}$

\section{Results}

Sixty four elderly patients were studied: mean age 80 (range 58-98 years); 22 were male. Fludrocortisone was prescribed for orthostatic hypotension in 17; vasodepressor carotid sinus syndrome in 19; combined vasodepressor carotid sinus syndrome and orthostatic hypotension in 14; combined vasodepressor carotid sinus syndrome and vasodepressor neurocardiogenic syndrome in four; combined vasodepressor neurocardiogenic syndrome and orthostatic hypotension in seven; and combined vasodepressor neurocardiogenic syndrome, orthostatic hypotension, and vasodepressor carotid sinus syndrome in three (figure). The mean duration of treatment was one year (range 2 to 21 months). The initial

Table 1 Primary causes of death in 13 patients who died during treatment with fludrocortisone

\begin{tabular}{llc}
\hline Causes of death & $\begin{array}{l}\text { Number of } \\
\text { patients }\end{array}$ & $\begin{array}{l}\text { Treatment duration } \\
\text { (mnth) }\end{array}$ \\
\hline Infection & 4 & 9 \\
Neoplasm & 6 & 5 \\
Myelodysplasia & 1 & 18 \\
Myocardial infarct & 1 & $0 \cdot 5$ \\
Aortic aneurysm & 1 & 5 \\
\hline
\end{tabular}

Table 2 Adverse events in 38 of 64 patients treated with fludrocortisone

\begin{tabular}{lclcl}
\hline Adverse event & $\begin{array}{l}\text { No of } \\
\text { patients }\end{array}$ & $\begin{array}{l}\text { Mean duration } \\
(\text { mnth) of treatment }\end{array}$ & $\begin{array}{l}\text { Mean dose } \\
(\mu \mathrm{g})\end{array}$ & $\begin{array}{l}\text { No of patients } \\
\text { withdrawn }\end{array}$ \\
\hline Cardiac failure & 7 & 7 & 93 & 7 \\
Systolic hypertension & 4 & 5 & 75 & 4 \\
Stroke & 1 & 2 & 100 & 1 \\
Depression & 3 & 4 & 100 & 3 \\
Hypokalaemia & 8 & 8 & 100 & 0 \\
No benefit & 2 & 3 & 75 & 2 \\
Deaths & 13 & 7 & 92 & 0 \\
\hline
\end{tabular}

daily doses of fludrocortisone were $50 \mu \mathrm{g}$ in 17 (27\%) patients, $100 \mu \mathrm{g}$ in $46(72 \%)$ patients, and $200 \mu \mathrm{g}$ in one patient. The dose of fludrocortisone was increased by increments of $50 \mathrm{mg}$ either until symptoms were abolished (for orthostatic hypotension, vasodepressor carotid sinus syndrome, and vasodepressor neurocardiogenic syndrome) or the orthostatic fall in systolic blood pressure was less than 10 $\mathrm{mm} \mathrm{Hg}$ (for orthostatic hypotension) or until adverse events occurred. Final doses of fludrocortisone were $50 \mu \mathrm{g}$ in $16(25 \%), 100 \mu \mathrm{g}$ in $38(59 \%)$, and $200 \mu \mathrm{g}$ in eight (12\%).

Adverse events occured in 38 patients: hypertension in four, cardiac failure in seven, hypertension and stroke in one, depression in three, and hypokalaemia in eight. Thirteen patients died during the follow up period (table 1) and two reported no treatment benefit and discontinued medication. Fludrocortisone was withdrawn in 17 patients after a mean of five months (range 1 day-12 months). Hypokalaemia developed at a mean of eight months (range 2-21); in no case was treatment withdrawn because of hypokalaemia (table 2).

\section{Discussion}

The prevalence of hypotensive disorders increases with advancing years. The commonest diagnoses are orthostatic hypotension, vasodepressor carotid sinus syndrome, and neurocardiogenic syndrome. These hypotensive diagnoses are responsible for symptoms in $43 \%$ of older patients referred to a specialist syncope service. ${ }^{8}$ A combination of one or more diagnoses occurs in $20 \% .{ }^{8}$ Treatment options for vasodepressor disorders are limited. Treatment includes practical manoeuvres (for example, stand slowly, avoid prolonged standing or Valsalva-like movements); physiological adjustments (for example, increased salt and fluid intake, elastic support garments, and elevation of the bed head); and pharmacological approaches. Drugs used are fludrocortisone, ${ }^{910}$ prostaglandin inhibitors, ${ }^{11}$ somatostatin analogues, ${ }^{12}$ dopaminergic antagonists, ${ }^{13}$ midodrine, ${ }^{14}{ }^{15}$ ergotamine, ${ }^{16}$ xamoterol, ${ }^{17}$ and fluoxetine. ${ }^{18}$

Fludrocortisone is generally regarded as the most effective first line treatment ${ }^{101219}$ in orthostatic hypotension. For the other treatments cited, the evidence for benefit is small or the occurrence of adverse effects is frequent or large intervention studies have not been reported. Studies of therapeutic options for the treatment of vasodepressor carotid sinus syndrome are even more limited. Preliminary data suggested benefit in symptom control and degree of carotid sinus vasodepression with fludrocortisone in the very old patients (mean 80 (5) years) who were treated for a six month period. However, supine systolic hypertension (mean 171 (37) $\mathrm{mm} \mathrm{Hg}$ ) developed in over half of these patients after only two weeks of treatment. " Treatment for recurrent neurocardiogenic syndrome which is predominantly vasodepressor also focuses on fludrocortisone, in addition to $\beta$-adrenergic blocking drugs, ${ }^{20}$ 
disopyramide, ${ }^{21} \alpha-1$ agonists ${ }^{15}$ and serotonin re-uptake inhibitors. ${ }^{22}$ However, no data from large randomised control studies are available.

$9 \alpha$-Fludrocortisone is a synthetic mineralocorticoid, which increases pressor sensitivity to circulating catecholamines and angiotensin, alters intravascular volume, and has central adrenergic effects. ${ }^{1}$ Its benefit in vasodepressor disorders is probably due to one or more of these physiological influences. Adverse effects have previously been reported in a small proportion of younger patients with idiopathic and diabetic orthostatic hypotension. ${ }^{29}$ In these patients, systolic hypertension and cardiac failure were attributed to sodium retention and plasma volume expansion. ${ }^{2}$ During long term treatment, it was noted that although plasma volumes returned to control levels, systolic blood pressure continued to rise because of enhanced peripheral vascular resistance. This was attributed to increased sensitivity to circulating catecholamines. ${ }^{2}$ In the present study, these adverse effects are even more frequent, although plasma volumes were not measured in this series. It is possible that patients who have an idiopathic relative reduction in plasma volume do better on fludrocortisone and have fewer side effects.

Increased susceptibility to adverse drug effects with advancing years is well documented. This is because of a combination of co-morbidity, polypharmacy, altered volume regulation, impaired baroreflex sensitivity, and age related changes in vascular resistance. ${ }^{23}$ In keeping with this, over a third of subjects experienced adverse effects during treatment with fludrocortisone and a quarter required withdrawal of drug therapy despite use of relatively low doses.

Fludrocortisone can be useful in the short term for symptomatic control of hypotensive disorders in the elderly. Fludrocortisone during prolonged treatment is poorly tolerated, even in low doses.

1 Bannister R, Mathias CJ. Management of postural hypotension in autonomic failure. In: Bannister $\mathrm{R}$ ed. Autonomic Nervous System: A textbook of clinical disorders of the autonomic nervous system. London: Oxford University Press, 1993;589-90.

2 Chobanian AV, Volicer L, Tifft C, Gavras H, Liang C,
Faxon D. Mineralocorticoid induced hypertension in patients with orthostatic hypotension. $N$ Engl $f \mathrm{Med}$ 1979;301:68-73.

3 Ewing DJ, Martyn CN, Young RJ, Clarke BF. The value of cardiovascular autonomic function tests: 10 years' experience in diabetes. Diabetes care 1985;8:491-8.

4 The Committee of the New York Heart Association. Diseases of the heart and blood vessels in nomenclature and criteria for diagnosis. 7th ed. Boston, 1973;286.

5 Kapoor WN. Diagnostic evaluation of syncope. $\mathrm{Am} \mathrm{f} \mathrm{Med}$ 1991;90:91-106.

6 McIntosh S, Lawson J, Kenny RA. The clinical characterisics of vasodepressor, cardioinhibitory and mixed carotid sinus syndrome in the elderly. Am F Med 1993;95:203-8.

7 Sutton R, Peterson M, Bringle M, Raviele A, Menozzi C, Giani P. Proposed classification for tilt induced vasovagal syncope. Eur 7 Card Pac Electrophys 1992;2:180-3.

8 McIntosh S, Da Costa D, Kenny RA. Outcome of an integrated approach to the investigation of dizziness, falls and syncope in elderly patients referred to a syncope clinic. Age Ageing 1993;22:53-8.

9 Campbell JW, Ewing IW, Clarke BJ. Therapeutic experience with fludrocortisone in diabetic postural hypotension. Br Med f 1976;i:872-4.

10 McIntosh S, Da Costa D, Kenny RA. Benefit of fludrocortisone in the treatment of symptomatic vasodepressor tisone in the treatment of symptomatic vasodepress

11 Watt SJ, Tooke JE, Perkins CM, Lee MR. The treatment of idiopathic hypotension: a combined fludrocotisone of idiopathic hypotension: a combined fludrocotison

12 Hoeldtke RD, Israel BC. Treatment of orthostatic hypotension with octreotide. Clin Endocrinol Metab 1989;68: 1051-9.

13 Lopes de Fria SR, Zanella MT, Andriolo A, Ribeiro AB. Peripheral dopaminergic blockade for the treatment of diabetic orthostatic hypotension. $\mathcal{f}$ Clin Pharma Ther 1988;44:670-4.

14 Kaufmann H, Brannan T, Krakoff L, Yahr MD, Mandeli J. Treatment of orthostatic hypotension due to autonomic failure with a peripheral alpha-adrenergic agonist (midodrine), Neurology 1988;38:951-6.

15 Ward C, Kenny RA. Observations on midodrine in a case of vasodepressor neurogenic syncope. Clin Aut Res 1995; 5:257-60.

16 Biaggioni I, Zygmunt D, Haile V, Robertson D. Pressor effect of inhaled ergotamine in orthostatic hypotension. effect of inhaled ergotamine

17 West JN, Stallard TJ, Dimmitt SB, Smith SA, Williams A, Littler W. Xamoterol in the treatment of orthostatic hypotension associated with multiple system atrophy: Shy-Drager syndrome. $Q \mathcal{F}$ Med 1990;74:209-13.

18 Grubb Blair P, Samoil D, Kosinski D, Wolfe D, Lorton M, Madu E. Fluoxetine hydrochloride for the treatment of severe refractory orthostatic hypotension. Am Heart $\mathcal{F}$ 1994;97:366-8.

19 Matsubara S, Sawa Y, Yokoji H, Takamori M. Shy Drager syndrome, effect of fludrocortisone and L-threo-3, 4dihydroxyphenyllserine on the blood pressure and regional cerebral blood flow. $\mathcal{f}$ Neurol Neurosurg Psychiat 1990;53:994-7.

20 Sra JS, Murphy VS, Shen YH, Troup PJ, Avital B. Use of intravenous esmolol to predict efficacy of oral betaadrenergic blocker therapy in patients with neurocardioadrenergic blocker therapy in patients with neur.

21 Milstein $S$ Buetikofer Junnigan A Benditt DG, Gornick C, Reyes WJ. Usefulness of disopyramide for Gornick C, Reyes WJ. Usefulness of disopyramide for prevention of upright tilt-induced hypoten

22 Kosinski DJ, Grubb BP, Temesy-Armos PN. The use of Kosinski DJ, Grubb BP, Temesy-Armos PN. The use of
serotonin re-uptake inhibitors in the treatment of neurally mediated cardiovascular disorders. $f$ Serotonin Res 1994;1:85-90

23 Lipsitz L. Abnormalities in blood pressure regulation. In: Kenny RA, ed. Syncope in the Elderly. London: Chapman and Hall, 1996;33-46. 


\section{LETTERS TO THE EDITOR}

Scope

Heart welcomes letters commenting on papers published in the journal in the previous six months. Topics not related to papers published earlier in the journal may be introduced as a letter: letters reporting original data may be sent for peer review.

\section{Presentation}

Letters should be:

- not more than 600 words and six references in length

- typed in double spacing (fax copies and paper copy only)

- signed by all authors.

They may contain short tables or a small figure. Please send a copy of your letter on disk. Full instructions to authors appear in the January 1997 issue of Heart (page 89).

Prospective relations between Helicobacter pylori infection, coronary heart disease and stroke in middle-aged men

SIR,-In our nested case-control study of Helicobacter pylori infection and coronary heart disease, ${ }^{1}$ based on the British Regional Heart Study cohort, men with pre-existing coronary heart disease were unintentionally under-represented among the controls selected ( $4 \% \vee 21 \%$ expected). This problem has been documented in the Lancet $^{2}$ in relation to a parallel study of the relation between homocysteine and stroke. However, the results of the study of $H$ pylori and its associations with coronary heart disease and stroke are not materially affected by this under-representation. This is emphasised by the results presented in the paper showing that the odds ratio associated with $H$ pylori infection for coronary heart disease was very similar if men with pre-existing disease were completely excluded. Our conclusion therefore remains unchanged.

PH WINCUP DALI IJ PERRY DP STRACHAN $M$ WALKER Department of Primary Care and Population Sciences Royal Free Hospital School of Medicine, Rowlands Hill Street, London NW3 2PF

1 Whincup PH, Mendall MA, Perry IJ, Strachan DP, Walker M. Prospective relations between Helicobacter pylori infection, coronary heart disease and stroke
men. Heart 1996;75:568-72.

2 Perry IJ. Serum homocysteine and risk of stroke [letter]. Lancet 1996;348:1526.

3 Perry IJ, Refsum H, Morris RW, Ebrahim SB Ueland PM, Shaper AG. Prospective study of serum total homocysteine concentration and risk of stroke in middle-aged British men. Lancet 1995;346:1395-8.

Probable right ventricular dysplasia and patent foramen ovale presenting with cyanosis and clubbing in a patient with characteristics of Noonan syndrome

SIR,-I report additional information on a case described by myself and $\mathrm{Da}$ Costa. The patient, who presented with cyanosis and clubbing, was described as having probable right ventricular dysplasia associated with patent foramen ovale. She also had characteristics of Noonan syndrome. Right ventricular endomyocardial biopsy specimens showed fibre hypertrophy, vacuolation, and degeneration with fine interstitial fibrosis; however, fatty infiltration was not seen. Despite the presence of one major criterion for diagnosis of right ventricular dysplasia (severe dilatation and reduced ejection fraction of the right ventricle without left ventricular impairment), and one minor criterion ( $T$ wave inversion in leads V1-V4 on ECG), there were insufficient criteria for definitive diagnosis of right ventricular dysplasia. $^{2}$

The original report pointed out that the patchy nature of fatty infiltration in the right ventricle can result in failure of endomyocardial biopsies to sample an area of fatty infiltration. Thus, the criteria used for diagnosis often prevents diagnosis during the patient's life; they are later confirmed at post mortem examination to have right ventricular dysplasia

Our patient has since undergone righ ventricular cardiomyopathy with closure of the foramen ovale (by Professor Sir Magdi Yacoub) with clinical benefit. Transmura biopsies taken at that time from the left ventricle were normal. Right ventricular biopsies showed no myocardial tissue bu extensive fibrous and fatty tissue (personal communication, Dr $\mathrm{M}$ Burke, consultan histopathologist, Mount Vernon Hospital, Middx). This additional information confirms that the patient satisfied the criteria for a diagnosis of right ventricular dysplasia. PETER WILMSHURST Royal Shrewsbury Hospital, Mytton Oak Road Shrewsbury $S Y 38 X Q$

1 Wilmshurst P, Da Costa P. Probable right ventricular dysplasia and patent foramen ovale presenting with cyanosis and clubbing in patient with characteristics of Noonan syndrome. Br Heart ₹ 1995;74:471-5.

2 McKenna WJ, Thiene G, Nava A, Fontaliran F, Blomstrom-Lundqvist C, Fontain G, et al, on behalf of the Task Force of the Workin Group Myocardial and Pericardial Disease of the European Society of Cardiology and of the Scientific Council on Cardiomyopathies of the International Society and Federation of the Internation of Cardiology, supported by the Schoepfe Association. Diagnosis of arrhythmogenic right ventricular dysplasia.
$B r$ Heart $₹ 1994 ; 71: 215-8$.

Echocardiographic evaluation of ventricular diastolic function: implications for treatment

SIR,-In their recent editorial Brecker and Gibson suggest an alternative approach to assessing the effects of treatment in diastolic dysfunction, namely to identify changes in diastolic measurements occurring with treatment that are known to increase exercise tolerance or improve prognosis.

Although exercise limitation is the obvious outcome for patients with clinically sig nificant diastolic dysfunction and indeed any functional limitation is likely to be more evident on exercise, nearly all studies report on resting parameters of diastolic performance. Despite increasingly widespread use of stress echocardiographic data in the definition of myocardial ischaemia, systolic dysfunction, and exercise related valve dysfunction, the role of exercise based echocardiographic indices of cardiac relaxation have to date been largely ignored. The reason for this is unclear.

Studies conducted during exercise may increase our ability to define abnormal relaxation and both link this directly to impairment of exercise capacity and assess the effects of candidate treatments. We have previously assessed the effects of brain natriuretic peptide (BNP) infusion on exercise haemodynamics in isolated diastolic dysfunction. ${ }^{2}$ We found that BNP significantly attenuated the exercise induced rise in pulmonary capillary wedge pressure in patients with diastolic dysfunction. In this study, we used invasive haemodynamic monitoring but it is our belief that exercise diastolic performance can be assessed non-invasively with Doppler echocardiography. To achieve this, non-invasive echocardiographic surrogate measures of ventricular filling pressure on exertion need to be explored and validated. $P$ SHIELS RJ MACFADYEN PO LIM TM MACDONALD Department of Clinical Pharmacology Ninewells Hospital $\mathcal{E}$ Medical School,
Dundee, DD1 $9 S Y$

1 Brecker SJD, Gibson DG. Echocardiographic evaluation of ventricular diastolic function implications for treatment. Heart 1996;76 386-7.

2 Clarkson PBM, MacFadyen RJ, Wheeldon NM, MacDonald TM. Effects of brain natriuretic peptide on exercise haemodynamics and neurohormones in isolated diastolic heart failure. Circulation 1996;93:2037-42.

\section{CORRECTIONS}

Fludrocortisone in the treatment of hypotensive disorders in the elderly

RM Hussain, Sf McIntosh, $\mathcal{f}$ Lawson, $R A$ Kenny (Heart 1996;76:507-9).

Under "Interventions" in the abstract it should have read: Fludrocortisone in daily doses of $100 \mu \mathrm{g}(72 \%), 50 \mu \mathrm{g}(27 \%)$, and $200 \mu \mathrm{g}$ (one patient). And not as published.

Effects of increasing flow rate on aortic stenotic indices: evidence from percutaneous transvenous balloon dilatation of the mitral valve in patients with combined aortic and mitral stenosis

T-M Lee, S-F Su, M-F Chen, C-S Liau, Y-T Lee (Heart 1996;76:490-4).

Dr Sheng-Fang Su's name was misspelled in the article.

NOTICES

The 1997 Annual Conference of the British Cardiac Society will take place at G-MEX, Manchester from 20-22 May. For further information, please contact the British Cardiac Society, 9 Fitzroy Square, London W1P 5AH. (Tel: +(0) 171383 3887; fax: +(0) 171388 0903; e-mail: bcs@rbh.nthames.nhs.uk) or visit «http:// www.bcs.rbh.nthames.nhs.uk $\gg$ on the Internet.

Asian-Pacific Cardiovascular Update will be held from June 5-6 in Hong Kong For further information, contact Professor JE Sanderson, Department of Medicine, Prince of Wales Hospital, Chinese University of Hong Kong. (e-mail: jesanderson@cuhk.edu.hk). 